\title{
De Divinatione de Cicerón en su contexto político y religioso
}

\author{
Cicero's De Divinatione in its political and religious context
}

\author{
DIONY GONZÁLEZ RENDÓN*
}

\begin{abstract}
RESUMEN
En medio de la ya desgastada relación que se daba en Roma entre religión y política a mediados de la década de los años 40.a.C, Cicerón escribió un diálogo sobre la religión llamado De Divinatione, que en más de dos libros, presenta un argumento que se sustenta especificamente en el tema de la adivinación. En este diálogo el autor latino reprueba y ataca fuertemente al final del tratado las creencias supersticiosas que se practicaban en esta época. Los magistrados romanos ya no recurrían a los arúspices para consultar los signos divinos en beneficio del Estado, sino que los manipulan para alcanzar sus intereses políticos. Pero en medio de esta fuerte reprobación por parte de Cicerón, también hay un intento por preservar y propagar la religión verdadera y defender las costumbres de los antepasados que han sido consagradas por el tiempo, la

mos maiorum.
\end{abstract}

\section{PALABRAS CLAVE:}

Adivinación, adivinación artificial, adivinación natural, predicción, augurio, religión, política.

\begin{abstract}
Amidst an already deteriorated relationship between religion and politics in Rome (40 BC), Cicero wrote a dialogue about religion called De Divinatione. The treatise is composed of two books in which Cicero addresses the subject of divination. At the end of this dialogue, he argues against the superstitious beliefs of his time, when the Roman magistrates, on behalf of the state, did not consult the auspices to read the divine signs anymore. Instead, they manipulated them to achieve their own political goals. Nevertheless, and despite of Cicero's determined condemnation of divination, there was also an attempt to preserve and spread the true religion, and defend the immemorial ancestors' customs, mos maiorum.
\end{abstract}

\section{KEYWORDS:}

Divination, artificial divination, natural divination, prediction, omen, religion, politics.

* Instituto de estudios clásicos Lucio Anneo Séneca, Universidad Carlos III de Madrid (C/ Madrid, 133. 28903 Getafe). E-mail: dgrendon@ inst.uc3m.es.

Artículo basado en la comunicación leída el 27 de Mayo de 2009, en la VIII edición del Encuentro de Jóvenes Investigadores de Historia Antigua de la Universidad Complutense de Madrid. 


\section{INTRODUCCIÓN}

Cicerón define la adivinación ${ }^{1}$ como la predicción e intuición de las cosas supuestamente venideras ${ }^{2}$. El Arpinate acepta algunas prácticas adivinatorias: por ejemplo, en De Republica y De Legibus, escritos entre los años 55 y 50 a.C. ${ }^{3}$, el derecho augural (Bayet 1955: 453-527; Tucher 1976: 171-177) juega un papel fundamental en la constitución de las leyes y en las funciones propias del legislador. Pero esta posición es diferente unos años después, ya que en De Natura Deorum, De Fato y De Divinatione, escritos en la década de los cuarenta ${ }^{4}$, hay una fuerte crítica por parte del mismo Cicerón ante toda manifestación supersticiosa ${ }^{5}$.

Esta evolución o cambio ideológico que se da en el autor latino y que se sustenta en su posición de la nueva academia, será el tema que vamos a analizar en el presente artículo. Veremos sucintamente la concepción que Cicerón posee de la adivinación sobre todo en el libro segundo de De Legibus ${ }^{6}$ y cómo, movido por una

1 Cicerón utiliza la denominación 'augur' para referirse al adivino en general, al intérprete del vuelo de las aves y al miembro del colegio romano de los augures, al que él mismo pertenecía. Sobre la etimología del término, tradicionalmente asociado con augure, ver Timpanaro (1988: 37-43), quien consideraba verosímil — dado que el rito podría no tener su origen en el ámbito agrícola — la vinculación con la raíz de avis y la del verbo gustare ('experimentar', 'valorar'; cf. Gr. geú ). También Cicerón en el libro II de De Divinatione utiliza el término harioli (Cic. Div. 2.10; también en ND 1.55) parar referirse en un tono irónico a los divini, los adivinos. También el término hariolus poseía a menudo connotaciones peyorativas (Pease 1979: 52).

${ }_{2}$ En Cic. Div. 1.9. El tema también había quedado aludido en Cic. ND2.12 y en Sen. Nat. 2.32.4.

3 Acerca de la publicación de De Legibus, ver: Att. 2.6.2, 14.17.6. También los siguientes estudios: Robinson (1949: 52), Grilli (1990: 22), Dick (2004: 5-7).

${ }_{4}$ Existen varias hipótesis (Durand 1903: 173-83) que han sido recuperadas por Pease (1979: 13-15) y Freyburger y Scheid (1992). Es uno de los últimos diálogos filosóficos de Cicerón, ya que ha sido escrito probablemente entre enero y marzo del 44, y retocado después del asesinato de César. De la misma confesión de su autor (Div. 1.4.7-5.8), esta obra debe ser puesta en relación directa con De Natura Deorum, que le es anterior, y estas dos constituyen con De Fato un conjunto indisociable. Dos alusiones por lo menos, en De Divinatione, anuncian De Fato (1.56.127 y 2.7.19) y, al principio de este último diálogo, Cicerón recuerda sus obras precedentes sobre los dioses y sobre la adivinación. Por otra parte, el tratado sobre la adivinación se presenta, desde el principio, como la continuación de De Natura Deorum. Quinto acaba de leer el libro de su hermano y desea recuperar la discusión sobre un punto que le parece haber sido descuidado, el problema de la adivinación, que es atado a los dioses pero que es preferible tratar aparte por razones de comodidad (Div. 1.9). Sea por la puesta en escena en De Divinatione o por las referencias intertextuales, el conjunto de las tres obras hay que concebirlo como un solo corpus, tal como se justifica en Schofield (1986: 47-65).

5 Sobre el concepto de superstición, en general, ver Cic. Nat. 2.72; Div. 1.7. También en la literatura griega puede consultarse en Thphr. Char. 16. Resulta difícil establecer con precisión el significado originario del termino superstitio, que de acuerdo con su posible etimología (superstes, 'verdadero testigo de lo pasado', a partir de super-stare), parece ofrecer un sentido más o menos positivo, divino profético, en algunos textos arcaicos, como se observa en el uso eniano de superstitiosus en 1.66 y 2.115, pero más bien negativo en otros (Cic. Div. 1.132), y que en esta época, en cualquier caso, ya parece haberse polarizado por completo frente a religio. Cf. Benveniste (1938: 35). Sobre esta cuestión, en general, puede consultarse Sachot (1991: 355-94). La delimitación entre religio y superstitio no parece haber estado siempre meridianamente clara entre los romanos de la época. Cf. Kroymann (1975: 116-28).

6 Otros textos del corpus ciceroniano donde es tratado el tema de la adivinación son los siguientes: Phil., en este texto es evidente la concepción que posee Cicerón sobre del derecho augural; también en $R e p .$, al igual que en $D e$ Legibus, es abordada la relación entre política y adivinación. Y finalmente en $D e$ Fato y De Natura Deorum, es evidente la relación entre adivinación y filosofía. El delicado estudio de Guillaimont (1984) analiza con detalle los aspectos mencionados. 
serie de sucesos políticos y motivos personales ${ }^{7}$, plantea unos años después una idea definitiva de la adivinación en su diálogo De Divinatione, conclusión que nos permitirá conocer uno de los primeros intentos en conformar un discurso científico filosófico sobre la religión romana ${ }^{8}$.

\section{DE DIVINATIONE EN SU CONTEXTO POLÍTICO Y CULTURAL}

De Divinatione es una obra de mucha mayor importancia para la historia de la religión que cualquier concentración exclusiva en los puntos de vista que su autor ha puesto de manifiesto. Su más notable característica positiva es el hecho de que se trata de un diálogo sobre la religión, que en más de dos libros presenta un argumento que se sustenta específicamente en el tema de la adivinación. Esto equivale a una clara indicación de uno de los más importantes acontecimientos religiosos de la República. No sólo fue un período caracterizado por un intenso interés en la religión, como ha sido tan bien documentado por Momigliano y Rawson ${ }^{9}$, sino que es un peróodo en que la 'religión', como una actividad y un tema, se define claramente indiferenciada de la relación político-religioso de la vida pública romana. Y es en esta relación entre política y religión donde enmarcaremos nuestro comentario.

En De Legibus nos encontramos con una primera posición por parte de Cicerón acerca de la adivinación; vale recordar en este punto que este texto fue escrito a finales de los años 50 a.C., antes de la tormenta de la guerra civil (Marinone: 2004). Cicerón plantea en el libro segundo de De Legibus (2.19-22), en un estilo arcaico, las leyes que se deben ajustar a la vida religiosa de la ciudad, las cuales no están muy alejadas de la tradicional legislación romana, tal como lo comprueba su interlocutor Ático (2.23). Cicerón, fiel a la tradición romana, hará intervenir la adivinación en la vida política de la ciudad ${ }^{10}$ :

7 Un período que comprende la proclamación del edicto que M. Antonio le concede a Cicerón, en el año 50 exactamente, y que le ordena abandonar Italia (Cic. Att. 11.7.2-9.1; Phil. 2.5), y también con el inicio de la segundad guerra civil, conflicto militar librado entre el 49 y el 45 a.C., protagonizado por el enfrentamiento personal entre Julio César con la facción tradicionalista y conservadora del senado liderada militarmente por Pompeyo Magno.

8 Cicerón hace derivar el termino de relegere, volver a leer escrupulosamente - de acuerdo con la que parece ser su verdadera etimología-, y no de religare, si bien, parece lo más probable que ambas connotaciones coexistiesen ya por entonces. Acerca del panorama religioso de la época, en general, puede consultarse ahora la síntesis publicada en Prise (1998:114-16).

9 Cf. Momigliano (1984a: 873-92; 1984b: 199-211), Linderski (1982: 12-38), Rawson (1985: 282-97; 1975: 241-245).

${ }_{10}$ La relación entre adivinación y política es evidente en el apartado 2.21 de De Legibus, donde queda que el conservadurismo religioso de Cicerón concuerda con el de Platón, sobre todo en los siguientes pasajes del corpus del autor griego: Pl. Leg. 738b-d, donde el ateniense recomienda respetar las prácticas religiosas tradicionales a la hora de fundar o de reconstruir una ciudad. Además aconseja no cambiar nada de lo que provenga de Delfos, Dodona o Amón. La importancia de Delfos como fuente de conocimiento de la ley también se puede ver en los siguientes pasajes: PI. Leg. 759c, 828a; Rep. $427 \mathrm{~b}-\mathrm{c}$, en este último pasaje se hace referencia a que a Apolo, dios de Delfos, corresponden las primeras ordenanzas, las más importantes y bellas: la fundación de los templos, la institución de sacrificios y otros servicios a los dioses, etc. No obstante, Platón limita la competencia de los oráculos al dominio religioso (Leg. 914a). Al principio de las Leyes (624a-b, 632d, 633a, 634a, 662c-d), nos hace referencia que Minos, Licurgo, estaban sometidos el conjunto de su legislación al control de Zeus o de Apolo. 
Interpretes autem loves Optimi Maximi, publici augures, signis et auspicis postera vidento, disciplinam tenento \{sacerdotesque\} vineta virgetaque et salutem populi auguranto; quique agent rem duelli quique popularem, auspicium praemonento, ollique obtemperanto. Divorumque iras providento, sisque apparento. Caelique fulgura regionibus ratis temperanto, urbemque et agros et templa liberata et effata habento. Quaeque augur iniusta nefasta vitiosa \{dira\} dixerit, irrita infectaque sunto. Quique non paruerit, capitale esto ${ }^{11}$.

Los augures del Estado, interpretes de Júpiter Optimo Máximo, que vean los acontecimientos que han de suceder en los presagios y en los auspicios; ellos deben conservar la disciplina tradicional, que los sacerdotes observen los augurios en relación a los viñedos y las plantaciones de mimbre para el bien del pueblo. Que los que vayan a emprender acciones de guerra o asuntos de Estado sean informados previamente por los auspicios, y a ellos obedezcan. Que prevean el enojo de los dioses y obedezcan sus deseos, que distingan en qué parte del cielo ha estallado el rayo. Que la ciudad, los campos y los pueblos mantengan libres y consagrados. $Y$ que todo lo que el augur declare injusto, nefasto, defectuoso y abominable sea nulo y como no sucedido, y quien no obedezca a los augures sea culpado de delito capital.

De esta manera, vemos cómo la utilidad política justifica el derecho augural $^{12}$ : Maximum autem et praestantissimum in re publica ius est augurum cum auctoritate coniunctum, «Pero el derecho mayor y el de más transcendencia en la República es el derecho augural, que va unido a la autoridad» (Leg. 2.31). Pero este valor que se le concede al derecho augural a partir de la eficacia política, no quiere decir que la legislación religiosa de Roma no revista ningún carácter consagrado ante los ojos de Cicerón; el enunciado de las leyes religiosas es precedido por un paso importante, donde Cicerón define la naturaleza de la ley. Para él, como para los estoicos, la ley verdadera se identifica con la razón divina: ratio est recta summi lovis, «es la recta razón del supremo Júpiter» (Leg, 2.10). Esta creencia en la existencia de los dioses conduce a Cicerón aceptar la adivinación (Leg. 2, 32):

Si enim deos ese concedimus, eorumque mente mundum regi, et eosdem hominum consulere generi, et posse nobis signa rerum futurum ostendere, non video cur ese divinationem negem.

Porque si admitimos la existencia de los dioses, y que su inteligencia dirige el mundo, y que aquellos velan por el género humano, y que pueden manifestarnos signos de las cosas futuras, no veo cómo pueda negar yo la adivinación ${ }^{13}$.

Pero ante esta posición por parte del Arpinate a favor de la adivinación, nos encontramos unos años después, entre los años 46 y 44 a.C., con una crítica que el mismo Cicerón hace de las diferentes manifestaciones de la adivinación, nos es-

11 Cic. Leg. 2.21.

12 También se puede ver en Brut. 1; Phil. 2.110. Bouché-Leclerq (1892: 557-58), Catalano (1960: 211-20), Wissowa (1912: 526), Blumenthal (1914: 249), Dumézil (1969: 97-98).

${ }_{13}$ Cf. Cic. Leg. 2.32; también en Cic. Div. 1.82-83, 104, 117. Esta idea la podemos percibir en el mundo griego en el Edipo Rey de Sófocles, 898-910; Arist. Frag. 12a Ross; Xen. Mem. 1.4.15. 
tamos refiriendo a la adivinación artificial —que comprende la aruspicina y apariciones «que son los intérpretes de señales ${ }^{14}$ y relámpagos» ${ }^{15}$, auspicios, tablillas y astrología- y la adivinación natural —que comprende los oráculos y los sueños- ${ }^{16}$.

Esta crítica que realiza Cicerón tendrá lugar en su obra De Divinatione, texto que se presenta como un diálogo entre Cicerón y su hermano Quinto, quien, conforme con la tradición heredada de Carnéades de las discusiones in utramque partem, de un pro y un contra ${ }^{17}$, defiende un modo de predicción que ataca luego el neoacadémico Marco. Sin embargo, en esta rápida presentación filosófica se ocultan dos dimensiones, religiosa y política, en el texto, las cuales serán analizadas a continuación.

\section{DE DIVINATIONE: UNA NUEVA POSTURA CICERONIANA ACERCA DE LA RELIGIÓN}

El punto de vista planteado por Marco Cicerón en De Legibus es próximo al que defenderá Quinto en el primer libro de De Divinatione. De una parte y de otra reencontramos el argumento del consenso seguro a todo riesgo de que las prácticas adivinatorias son difundidas entre todos los pueblos, atestiguadas en cada época, universalidad que sería inexplicable si se le negara toda posibilidad a la mántica (Div. 1.11-12, 84). Aparece también el silogismo estoico que deduce la realidad de la adivinación a partir de la existencia de los dioses: los dioses existen, y en su benevolencia para los hombres, les revelan un futuro que no pueden ignorar, ya que es ajustado por su providencia (Div. 1.82-84). Finalmente, numerosos ejemplos, históricos o legendarios, son comunes en ambas exposiciones. Pero en el libro segundo de De Divinatione, la posición de Cicerón en relación a la planteada en De Legibus es diferente, tal como veremos a continuación. Desde hace tiempo los comentaristas quisieron dar cuenta de la contradicción que se puede desprender entre De Legibus y De Divinatione. Varias suertes de explicaciones han sido propuestas. Para unos, Cicerón hablaría del lado del hombre político, deseoso de justificar las instituciones romanas, del otro lado el filosofo, buscando la verdad por sí misma haciendo abstracción de sus incidencias prácticas (Goar 1972: 103; Kroymann 1975a: 123); para otros, el pensamiento ciceroniano habría cono-

14 Se entiende que como signo de buen presagio en ambos casos (Cic. Div. 1.85); también en PI. As. 260-61, se considera de buen augurio el canto de la corneja cuando se produce por la izquierda, y el del cuervo cuando lo hace por la derecha - picus et cornix ab laeva, corvos, parra ab dextera / consuadent-. Cf. así mismo Aulul. 624, a propósito del cuervo, animal que se encargó de anunciar a Cicerón su propia muerte, según refiere Plutarco (Cic. 47.8); ejemplos discordantes, como los de Verg. Ecl. 9.15, y Hor. Carm. 3.27.15-16, podrían estar reflejando, más bien, un uso griego.

15 Los etruscos poseían toda una teoría elaborada sobre la interpretación de los relámpagos.

${ }_{16}$ Cf. PI. Phdr. 244d; la distinción entre adivinación 'artificial' —obtenida mediante la aplicación de una técnica (ars), cuya aplicación está en la base de la interpretación (interpretatio) y de la posterior coniectura (2.66) - y adivinación 'natural' es bastante recurrente en esta obra (cf. Cic. Div. 1.34, 72, 109; 2.26-27, etc.), tras el probable precedente de Posidonio.

17 Acerca de la definición que hace Cicerón de este tipo de argumentación, ver Tus. 2.9; Def. 5.10. 
cido, en este dominio, una evolución profunda ${ }^{18}$. A continuación mencionaremos algunas de estas tesis y a partir de ellas construiremos una conclusión que nos permitirá comprender la pretensión, a nuestro parecer, que poseía Cicerón en su diálogo De Divinatione.

Linderski (1982: 16) plantea la pregunta de por qué Cicerón estaba tan determinado a abolir las creencias en toda forma de adivinación. Según él, las razones no son solamente filosóficas, sino también políticas. La hostilidad ciceroniana contra la mántica se explicaría, en última instancia, por el hecho de que la adivinación romana estaba bajo la autoridad de César. Por otro lado, Momigliano ${ }^{19}$ describe la evolución de Cicerón de un modo que a nuestro parecer no es tan adecuada, ya que enmarca el escepticismo de Cicerón como una simple critica a la teología estoica y no tiene en cuenta el hecho de la importancia de la adivinación en la religión oficial de Roma.

Blänsdorf (1991: 45-65) y Carlos Lévy (1992: 585-87) formularon, independientemente uno del otro, una hipótesis que consideramos mucho más convincente que las anteriormente evocadas, ya que según sus hipótesis, el rechazo de la adivinación por parte de Cicerón debe ser puesto en contacto con su experiencia de la guerra civil. Las predicciones innumerables hechas por los arúspices o los astrólogos entonces se revelaron mentirosas, y sobre todo el emperador vencedor fue el que se atrevió a despreciar los consejos de los adivinos ${ }^{20}$. Cicerón establece un contraste entre la confianza de Pompeyo - por creer en todo lo que le decían los arúspices- y la libertad de espíritu de Cesar, que no vaciló en atravesar el mar a pesar de que lo desaconjera el sumo arúspice, asegurándose así la victoria. Cicerón plantea que durante la guerra civil muchas palabras de los dioses inmortales fueron arropadas por la mentira. Al respecto escribe Lévy (1992: 587): «Es la capacidad de los adivinadores que se equivocan casi sistemáticamente, y con consecuentes tan trágicos, que arruinó en Cicerón hasta la esperanza de un mántica verdadera». Esta hipótesis nos permitirá mostrar que De Divinatione sumerge sus raíces en la experiencia personal de Cicerón.

Pero antes de plantear cualquier tipo de conclusión, es necesario aclarar que De Divinatione corresponde a una postura definitiva y que expresa el escepticismo personal de Cicerón con respecto a la adivinación, condena fuertemente la superstición, pero esta crítica no supone una condena contra la religión, y aunque Cicerón en el año 45 a.C. enmarca su pensamiento en la nueva academia, aún sigue latente la idea de defender y de propagar las costumbres de los antepasados, mos maiorum, manteniendo las ceremonias religiosas ${ }^{21}$ y la creencia en los dioses, ya

18 Schmidt nos dice que De Legibus presenta el primer estado del pensamiento ciceroniano, a un Cicerón más respetuoso con la religión tradicional, antes del estudio sistemático de la pregunta, y la postura definitiva, que se traduciría en De Divinatione (Schmidt 1959: 220).

19 Momigliano (1984b: 199-211).

20 Cic. Div. 2.52-53, 2.99. Acerca de este pasaje, ver Rawson (1978: 132-52).

21 Cicerón mismo, en su requisitoria del libro II de De Divinatione, considera sin embargo que las prácticas divinatorias propiamente romanas deben ser respetadas en el mismo interés del Estado. La idea también es recurrente en Cic. Har. 61-62, donde Cicerón argumenta sobre la necesidad de mantener la tradición religiosa, el arte y el derecho augural para el bien del Estado. 
que la misma belleza del mundo, el orden que reina entre los cuerpos celestes, nos obligan a reconocer la existencia de una naturaleza superior y eterna, a la que el género humano debe admiración y respeto.

Así pues, la crítica de la adivinación por parte de Cicerón se inscribe precisamente en este marco, en un clima político en el que hay una invasión de los ritos adivinatorios y una manipulación de éstos. La adivinación se convierte en una herramienta política en las manos de los partidos o de los individuos simples. Los ejemplos alegados por Marco son significativos, comparables a las ilustraciones literarias utilizadas por su hermano Quinto, ya que el orador sustituye referencias a la historia, y sobre todo a la historia reciente. Cicerón toma a broma así al toro sin corazón inmolado por César (Div. 2.64), y otros ejemplos citados en el libro II.

Pero al fin de la República, las cosas van más lejos: no basta que las prácticas adivinatorias se multipliquen y que sean objeto de falsificaciones. También el simbolismo augural, los sueños y las predicciones de los arúspices juegan un papel importante en la propaganda política en el curso de las guerras civiles, y los órganos religiosos cargados de arúspices casi se encuentran tomados de rehén por los diferentes partidos. Al desconocer el valor de la adivinación a favor de la res publica, los políticos se dirigen a los arúspices con el único fin de salir victoriosos en sus propias ambiciones. De esta forma, tal como lo afirma Guillaumont (1984: 70), la práctica augural ya no tiene que ver con los honores religiosos sino que se convirtieron en armas políticas.

Vemos que Cicerón argumenta con su crítica la pérdida de la armonía entre el hombre y lo divino. Así, para los espíritus fuertes, los signos divinos, contrariamente a todo lo que ha sido citado hasta aquí, ceden el paso delante de las exigencias morales. Durante la guerra civil en Roma los valores morales sufren, al igual que los ritos tradicionales de la adivinación, una degeneración. En la capital del Imperio existe, para Cicerón, una analogía entre el progreso del Estado y el progreso moral, correlativamente la decadencia del Estado y la decadencia moral de los individuos entran en el mismo campo. Desde entonces, devolver sentido a los valores éticos debe permitir alejar al Estado de la dictadura. En suma, las vibraciones que todo lector puede fácilmente percibir de la lectura del libro II de $D e$ Divinatione se explican, en última instancia, por la inversión particular de Cicerón porque este diálogo toma sus raíces en la experiencia personal de su autor.

Podemos concluir que la radicalización del discurso ciceroniano contra toda forma de adivinación es enlazada con el contexto social, político y religioso de la época. No es por supuesto que, como plantea Mary Beard (1986: 33-46), el tratamiento de la religión del Estado en las obras filosóficas de Cicerón, sin reducirse a una presentación argumentada sobre una opinión o sobre una idea, constituye más bien el proceso de formación de un discurso sobre la teología. Pero para nosotros, De Divinatione puede ser leído como una respuesta oportuna a un estado de la sociedad que Cicerón condenaba y en la cual, es más, no tenía más sitio. Pero, más profundamente, comprobando que la dictadura política está reemplazando a la dictadura militar, él se une, parece, a través de la trilogía de De Natura Deorum, De Divinatione y De Fato, textos que recuerdan los verdaderos valores individuales y 
colectivos de Roma, a espíritus obnubilados por la superstición y cegados por las manipulaciones políticas.

\section{BIBLIOGRAFÍA}

BAYET. J. (1955), «Les sacerdotes romains et la pre-divinisation impériale», BAB 41, 453527.

BEARD, M.; NORTH, J. y PRICE, S. (1998), Religions of Rome. A History, Cambridge.

BEART, M. (1986), "Cicero and divination: the formation if a Latin discourse», JRS 76, 33-46.

BENVENISTE, É. (1983), «Religión y superstición», en Vocabulario de las Instituciones Indoeuropeas, 2 vols., Madrid.

BLÄNSDORF, J. (1991), Augurenlächeln. Ciceros Kritik an der römischen Mantik dans Zur Erschliessung von Zukunft in den Religionen, Würzburg.

BOUCHÉ-LECLERQ, A. (1892), Dictionnaire des Antiquités Grecques et Romaines, Paris.

CATALANO, P. (1960), Contributi allo Studio del Diritto Augurale, Torino.

DUMÉZIL, G. (1969), Idées Romaines, Paris.

DURAND, R. (1903), "La date du De Divinatione», Mélanges Boissier, 173-183.

DYCK, A.R. (2004), A Commentary on Cicero De Legibus, Ann Arbor.

FREYBURGER, G. y Scheid, J. (1992), Cicéron De Divination, Paris.

GOAR, R. J. (1972), Cicero and the State Religión, Amsterdam.

GRILLI, A. (1990), «Data e senso del De Legibus di Cicerone», PP 45, 175-187.

GUILLAIMONT, F. (1984), Philosophie et Augure: Recherches sur la Théorie Cicéronienne de la Divination, Bruxelles.

- (2006), Le 'De divinatione' de Cicéron et les Théories Antiques de la Divination, Bruxelles.

KROYMANN, J. (1975), Cicero und die römische Religion, Leiden.

LINDERSKI, J. (1982), «Cicero and Roman divination», PP 37, 12-38.

LÉVY, C. (1992), Cicero Academicus. Recherches sur les Académiques et sur la Philosophie Cicéronienne, Paris.

MOMIGLIANO, A. (1984a), «Religion in Athens, Rome and Jerusalem in the first century BC», AnnScNormPisa 3.14, 873-92.

- (1984b), «The theological efforts of the Roman upper classes in the first century BC», CPh 79, 199-211.

MARINONE, N. (2004), Cronologia Ciceroniana, Roma.

PEASE, A. (1979), M. Tulli Ciceronis De Divinatione, New York.

RAWSON, E. (1975), Cicero: A Portrait, Bristol.

- (1978). «Etruria and the disciplina etrusca», JRS 68, 132-152

- (1985), Intellectual Life in the Late Roman Republic, London.

ROBINSON, A. (1949), «The date of Cicero's De Legibus», TAPhA 77., 37-82.

SACHOT, M. (1991), «Religio/ superstitio. Histoire d'une subversion et d'un retournement», Revue de l'Histoire des Religions 208, 355-394.

SCHMIDT (1959), Die Abfassungszeit von Ciceros Schrift über die Gesetze, Roma.

SCHOFIELD, M. (1986), «Cicero for and against divination», JRS 76, 47-65.

TIMPANARO (1988), Della Divinatione, Milano.

WAYNER TUCHER, C. (1976), «Cicero, Augur, De iure augurali», ClassW 171-177.

WISSOWA, G. (1912), Religion und Kultos der Römer, Munich. 